\title{
Poetries, Micropoetries, Micropoetics
}

\author{
Maria Damon
}

I liked absurd paintings, pictures over doorways, stage sets, carnival backdrops, billboards, colored prints, old-fashioned literature, Church Latin, erotic books badly spelled, the kind of novels our grandmothers read, fairy tales, little children's books, old operas, silly refrains, naive rhythms.

$$
\text { Arthur Rimbaud, "Alchemy of the Word" }
$$

\section{Micropoetries}

Ephemera, doggerel, fragments, "weird English" (props to Evelyn Ch'ien), graffiti, community and individual survival-écriture brute, folk letters, textile patterns evocative of "writing"; naive lettrism (as well as belletrisme and lettrisme brute); wise oraliture, gnomic thought-bytes and lyrical bullets, clairaudient visitations with a hermeneutic spin-traces of (in)decipherability; banality morphed into something more-

-the marriage of esotericism and exotericism, banality and exoticism. Embedded in contextual specificity (socio-historical etc.) but deracinated - the historic exile, the monadic nomad, the centrifugal community that lets fly its auratic verbal detritus.

Maria Damon is Associate Professor of English at the University of Minnesota. She is the author of many essays on poetry and poetics as well as The Dark End of the Street: Margins in American Vanguard Poetry, co-author (with mIEKAL aND) of Literature Nation, Eros/ion, and pleasureTEXTpossession, and co-editor (with Ira Livingston) of the forthcoming Poetry and Cultural Studies: A Reader. 
These are poetries that fly beneath the radar of accepted poetic practice, that is not practice but object-these are processes rather than object/products. I've explained the term elsewhere as indebted to Mark Slobin's term "micromusics" (Subcultural Sounds: Micromusics of the West) by which he means fragments, lullabies, tunes, extremely localized bits of expressive culture carried from the Eastern Europe pale of settlement to New York in the great migrations 1880-1940: individual shtetlach (village-ghettoes), families', locales' unique musics that made the journey and metamorphosed, somehow surviving. This is also the resonance of W. E. B. Du Bois's anecdote in "Of the Sorrow Songs," wherein he tells of his grandfather's grandmother bringing a song with her which traveled not only spatially across the Middle Passage but temporally down the generations to have been sung to him when he was a small child. He prints the music, transliterating syllables he doesn't understand, and from that archaeological fragment constructs a theory of cultural transmission.

And thus was born a Cultural Studies: the presence of fire in resonant landscapes-resonant for the ones with big ears. ${ }^{1}$

(Damon, "Micropoetries," 235)

\section{Revisitation}

"Poetries" and "micropoetries" might intuitively seem to function as analogies to "cultures" and "microcultures," or out-of-the-way subcultures. When I was asked to contribute to a special issue on this inviting "poetries" topic, the note from the co-editor asked me to "recalibrate what 'micropoetries' are and what 'micropoetics' do?" (Is its current calibration inadequate?) What reading am I doing that is helping me to put together ideas that could be of use to other scholars? Would I like to write a review essay covering about six to ten of the books I've found most useful? (You will find a more systematic response to this series of questions in the last section of this essay.) What I find most inspiring is the current swell of interest in the matrix of poetry, poetics, and cultural studies. Despite its arrival some twenty to thirty years after the heyday of Birmingham School-style cultural studies, this gesture toward a systematic academic approach to poetryand-cultural-studies has just begun, though of course there is a prehistory as well as a groundswell of current work. This special issue is itself part of a larger sweep that suggests that some kind of moment has been reached. The last few years the MLA's poetry division has been going in a positive direction (poetry and war, poetry and the global/local, poetries), and a recent call for papers for a special session was titled "Cultural Studies and Poetics." My co-editor Ira Livingston and I have at long last found a publisher for our Poetry and Cultural Studies: A Reader; the conflicting readers' reports it left in its wake en route to contractuality (contractual actuality) embodies precisely the agonistic terms in which a meeting of "poetry and cultural studies" is experienced by contemporary poetry scholars. Everyone who learned about the volume or read some part of it agreed that "something like 
this is needed," timely and urgent; no one agreed on what it should comprise. One reader said not enough women/folks of color; another said, in effect, not enough dead white men (i.e. "traditional" poetry or selections that dealt with pre-WWII material). One reader hated about half the poetry we wanted to include; the other reader hated the other half of the poetry, and neither was shy about flaunting personal taste as a bellwether ("forgive my lack of enthusiasm for X's poetry" was offered without analytic qualifiers), rather than asking what cultural work each selection performed. It was "the debate" in nuce. So I'm delighted at the moment and at the same time fearful that I will miss it, the fruition of a lifetime's vision, so busy tub-thumping for the poetry-n-cultural-studies cause as an idea that I miss actually-existing analyses that are quite compelling.

Anxiety comes up because no, I have not read six to ten books that have enabled me to further my thinking about micropoetries (again, see the final section for an elaborated retraction of this admission). There are no books explicitly on the subject; micropoetries are not generally published as books other than in self-published venues or in out of the way ventures; poets and poetry scholars still want the big-time and eschew the double marginalization they experience from being categorized as "micro" (that is, nobody wants to be considered a micropoet); studies of graffiti artists by sociologists or ethnographers turning to work on the local or to (sub)cultural poetics tend for the most part to shy away from claims about "poetry" (with some notable exceptions, all of whom work in the Middle East: Stephen Caton's study of "poetry as social practice" in a Northern Yemeni tribe, Lila Abu-Lughod's early work on gender in Bedouin poetry, and W. Flagg Miller, who writes about cassette culture and political poetry's circulation in Yemen).

Many have found the term "micropoetries" to be too inexact to be tremendously useful: is it "found poetry" tout court? Well, no, though that might be a subset thereof. Is it synonymous with doggerel, as I was asked somewhat incredulously after delivering a paper on the subject at an MLA special session on "Poetics Out of Bounds"? No, though I've sometimes delivered such papers in the persona of Mademoiselle Doggerelle. The term (micropoetries, not Mlle. D) is deliberately loose and capacious, intended to encompass a range of para-literary instances of expressive culture that somehow function as a shard which, optimally, as in Du Bois's lullaby-fragment in "Of the Sorrow Songs," can become the basis for a theory of culture (in that instance, a theory of cultural transmission); or as the opening chapters of Henry Louis Gates's now-canonical The Signifying Monkey posit an anonymous urban ballad as a springboard for a theory of reception and production of African American "high" literature. Micropoetries are intensely context-specific and may require great elaborations from their analysts in order to convey their full significance; in this, the attempt to overcome the "you had to be there" quality inherent in micropoetic power, the critic becomes a "thick description" ethnographer, or an over-amped Tom Wolfe of litcrit, crazily trying to summon the ambience in which the micropoetic moment achieved the epiphantic. One might imagine my own early essay "Tell Them About Us," about the poetry of teenaged women in a South Boston housing project, as an amateur foray into ethnographic writing; it was not entirely intended as such, though it had its genesis in a seminar with anthropologist Renato Rosaldo on "Stories in Culture." 
With regard to the aforementioned capaciousness, I see the concept of "Poetries" as a direct descendant of "micropoetries," which I originally attempted to instantiate by lists including

graffiti as language, poetry therapies, prison poetry, a relative's topical verse, the history of fortune cookies, the use of modernist conventions (linebreaks, the belief in the sudden private aperçu) to market corporate slogans lasered in gothic script onto wooden plaques ... they could also be pre-slam colloquial, vernacular poetry [...] sound that contributes to a texture of living in forgotten places (Damon, "Post-literary Poetry," 42),

and by emphasizing that

the question would be: "What cultural work does this artifact or this poetic event accomplish?" It would be impossible to isolate the event from its context; artifact and event would be inseparably implicated in each other ... (Ibid.)

a roster and an intellectual agenda echoed fairly closely and elaborated in the bulleted list in the Call for Papers for this special issue and in the brief description of the related upcoming MLA panel: "prison poetries, scrapbooks and journals, newspaper poetries with an eye toward poetry as a dense field of social interactions." In a sense "micropoetries" occupies the space that "poetries" has now come to share through this set of initiatives, though perhaps with a somewhat spectral presence rendered even more so by its bolder, newer incarnation, and subsumed within it. One might say that "poetries" is the academic rehabilitation, the "making-useful," the "coming-of-age," of "micropoetries," which may have to remain furtive and idiosyncratic in order to retain its purchase, the usefulness of any contrarian friction it may continue to represent, on literary studies. (For example, mainstream publishers in the early 1970s rushed to publish anthologies of prison poetry, but to my knowledge this is its first mention in an MLA panel description. There is a good chance, however, that the ASA [American Studies Association] convention, representing an explicitly interdisciplinary field, has already seen a number of such panels.) To be sure, if one googles "poetries" tout court, one finds a range reaching into the high aether of the avant-garde and the broad ripples of middlebrow taste in production/consumption, indicating that the term need not be restricted to the non-canonical or the para-literary; but this special issue and the MLA panel organized in concert with it have clearly aligned with the outer reaches delineated by "micropoetries," to wit:

The Iowa Journal of Cultural Studies seeks contributions for a special issue, possible book project, and major conference presentation on the topic of "Poetries." Our focus is not The Poem but the range and multiplicity of poetries made newly visible by recent developments in cultural studies, performance studies, everyday life studies, book studies, etc. We are looking for es- 
says that position poems as part of the material conditions, technologies, and social histories of their moments. Contributors are encouraged to think broadly about poetic utterances, the acts such utterances perform, and the intentional and unintentional effects they have in specific contexts and communities as they get produced, distributed, used and consumed as cultural phenomena. As we wish to invite broad consideration of poetries, poems, poetry criticisms and their communities, there are no restrictions on period or place.

Essays may address, but are not limited to, the following kinds of topics:

- Poetry and the public landscape

- Poetry and politics (e.g., political poetry, poetry and activism, poet laureates)

- Poetry and technology

- Poetry in performance (e.g., slam poetry, poet's theater, poetry and performativity, etc.)

- Poetry and, in, or as commodity culture

- Poetry in specific institutional settings (e.g. prisons, high schools, the workplace, writers workshops, chat rooms, etc.)

- Poems issued or excerpted on posters, cards or broadsides; collected in scrapbooks or printed in newspapers; appearing or referenced in film, television or video

- Poetry, visual arts and material culture

- Documentary poems

- Poems by hoaxers, plagiarizers and polemicists

- "Micropoetries" (Damon's term) such as greeting card verse, lullabies, playground rhymes, and occasional poems

If, then, "poetries" as currently envisioned in this project basically recapitulates "micropoetries" in a mainstreaming moment, what is lost and what is gained by dropping the minoritizing prefix? "Poetries" accomplishes and/or promises (at least) two things not anticipated by "micropoetries": it implicitly includes standard literary poetry, which "micropoetries" explicitly excludes; and it indicates clearly that a wider understanding of poetry and the social, as well as and especially intellectual curiosity about it, has become institutionally acceptable, indeed has become a potential source of cultural capital for the scholar who undertakes such study. What then, if anything, could be useful about hanging onto the cranky prefix? Is it symptomatic perhaps of a superannuated and stubborn clinging to margins that are no longer marginal? Or perhaps a desire to find ever more edgy edges, ever more nervous systems (in Michael Taussig's terminology), ever more tracy traces? Is it the "local" to "poetries"" "global," acting in productively inseparable concert with it? Micropoetries comprise traces of the "poetic" within the everyday, unworked over; that is, "raw material" left raw instead of being cooked into artistically self-conscious collage, pastiche, "retelling," or other incorporative literary genre. Micropoetries is conversely also the banal that raises its spectrally perverse dreadhead in the field of the "poetic"; the clunker, the cringe-worthy line, the obstinate appearance of the groaner in a field of niceness; a micropoetry analysis might be a way of redeeming the banal by grasping its socio- 
historical and affective hauntings. It becomes a way, furthermore, to honor the Kristevan "thetic" rupture of normative, seamless discourse, whether that discourse is a blandly acceptable "poetic" one disturbed by "wrongness" or topdownly organized urban landscapes marked with some arresting graffiti or bricolaged outdoor home decorating. The emergent "Flarf" poets are masters of parody of this particular enactment of poetic "badness" that most literati love to hate but some of us find endearing, eyeopening, and socially as well as aesthetically interesting. The Flarf collective, a group of "serious" "avant-garde" poets ("poets") operating primarily as a listserv, specializes in such revelrous badness - sentimentality, violence, clichéd banality, politically incorrect bloopers in manic send-ups of "poetry"'s pretensions. (Flarf would be a borderline case of "micropoetries," though it is definitely a "poetry" because of its high degree of ironic, sophisticated self-reflexivity.) But "micropoetics" is also, conversely, the appearance of what would otherwise be doggerel in contexts that render it dignified, moving, appropriate: the child's poem read at her father's funeral, for instance. "Daddy, daddy, why'd you leave / and left me sitting here to grieve?" at a Cape Verdean funeral in Falmouth, Massachusetts, after the young father of three died in a early-morning car accident in which the standard, euphemistic "driver lost control of the vehicle" tells part of the story....

Some of the difficulty I've had with trying to mainstream the term: "micropoetries" may be too self-marginalizing a term to be useful to scholars at large. Does it marginalize what doesn't warrant or desire marginalization, in spite of its clear distance from either academic or middlebrow mainstream? "Micro" to whom, by what measurement? Marginal to what ever-moving, ever-morphing center? One very thoughtful undergraduate student, who wanted to write about his autistic sister's writing for his "micropoetries" assignment (a staple in my undergraduate teaching repertoire), was troubled by the "micro-"izing effect of the term, even as he understood that her writing would not be considered seriously as such by the mainstream, nor did he want to treat it as symptomatic or epiphenomenal to her illness, or, for that matter, to see her illness as a stigma. "Poetries," by contrast, elegantly and tactfully addresses this embarrassment by erasing signs of hierarchy and exclusion.

As in Mark Slobin's analysis of his own coinage "micromusics," "micropoetries" do not have an exclusionary and isolationist relation to commercial, academic or, in Charles Bernstein's effective shorthand, "official verse culture" - it continues to inform and replenish it whether through oppositional friction or commodificationmuch as poetry as "anti-discourse" (Karlheinz Stierle's contention) lives side-byside with and in continual polylogue with institutionalized, "prosaic" discourse. On the contrary, in their original conception, micropoetries fully involved analyses of mass-cultural and commercial artifacts (poetry on beer caps, tea-bag packaging, coat-tail-riding nomenclature like "Baudelaire Beauty Products," greeting cards and billboards as well as hip-hop and street jive, whose commodification as well as ongoing potential for ever-renewable, productive friction has been well-documented). But one can fruitfully explore the fluid relations of the not-quite-assimilable

- that is, a limbo mediating the generally acknowledged world of "art" on the one hand and on the other, the kitschy demimonde Rimbaud 
enumerates at the opening of this paper: "billboards ... erotic books badly spelled ... silly refrains, naive rhythms"-comprising 'zines, liminal literary productions such as the spoken word world, or the new media work of outsider/pioneer/insiders like rural anarchist mIEKAL aND, whose preoccupation with the continuum between plant-life and cyberspace life-forms informs the projects of his visionary community DreamtimeVillage, in WestLima, Wisconsin, including the press Xexoxial Editions and digital/film/video production group Driftless Media; Australian feminist artist mez (Mary Anne Breeze), whose invented language Mezangelle dis/articulates the mutilations and multi-ululations of internet language reinvented as bleeding code; and Brooklyn-based factotum Alan Sondheim who coined the now standard descriptor "codework" for an electronic poetry aesthetic that foregrounds the language, usually hidden, of computer programming itself, yet remains marginal to the burgeoning world of "new media creative writing" -

with mainstreaming mechanisms such as MFA programs, academic conferences, and publications such as this one. This is what the rubric "poetries" adds to the mutating landscape of poetry studies; by leveling that landscape, it forces a revaluation, perhaps a more subtle recalibration ("recalibration"), of the power relations so starkly announced in the antecedent term.

\section{Elegiac Visitation}

However, micropoetries continue to bubble up furtively both as object of study and as ephemeral phenomena. As suggested earlier, many of these instances are elegiac, though that word feels inappropriately leisurely and retrospective ("contemplative," my mid-level dictionary has it), while the emotions that fuel an expression of loss are often extreme and desperate rather than wistful and pensive. Peter Sacks has written of the origin of the mourner's elegy in a matrix of funeral rituals (stemming, even earlier, from rituals surrounding the cycle of vegetation dieties' deaths and rebirths) including processions, wind instrument performance ("the flute song of grief”'), and human song in an attempt to make absence present ( $3 \mathrm{ff}$ ). The elegiac poem itself, like Apollo's wreath, is a made object intended to represent and magnify the departed; the object, again like the laurel wreath, accrues meaning of its own beyond that of memento; it becomes a vehicle for creativity. For many people who do not identify as "professional" poets, poetry functions as an emotional as well as linguistic technology that is particularly apposite for moments when affect exceeds linguistic expression; poetry is a valuable resource because of its overdetermined and compressed nature. Here is a poem written by my friend Susan Lannen, who does not self-identify as a poet, about her daughter Ariel Alyssum, who died at twenty-five of a heroin overdose in the summer of 2005. Since Ariel's death, Susan has been unable to leave poetry alone, and her words about it, when I asked her what role words have played in her mourning process, confirm its usefulness for her: "I don't know about words, but for poetry, it's the new love in my life since Ariel's death. I think there's something about poetry that says it without wearing you out by saying too much; especially for a grieving person to be given words that are really dense and full is really helpful.... It's like medicine, 
concentrated." Months after Ariel's death, the Phoenix (Boston's alternative weekly newspaper) ran an online article on memorial sites on MySpace, in which friends and e-quaintances continue to write to someone's account even after that person's death or disappearance, as a way of staying in touch, mourning, memorializing, processing. The article had focused in large part on Ariel, whose MySpace name was/is äRRiel, and whose account featured her vivid writing on her experiences as a runaway, a street kid, a homeless person. You can experience it at www.myspace.com/aRRiel, http://arrielgurl.livejournal.com/, or her site "Cardboard Box," at www.geocities.com/little_sister_shotgun/

\section{Ariel:aRRiel \\ A Reflection on a Virtual Memorial by Susan Lannen}

Death: ordinary shadows absorbed reflections screened out, darker now. Her name though not in any phonebook nor etched in stone, Is simultaneously entombed and resurrected in cyberspace, and can be occasionally found scrawled on the cover of a book of matches

that could still set a fire, now quietly resting, however, next to a number that won't reach her anymore.

Having consumed the Nothing and been consumed by it She is Nowhere.

Not on the morning shuttle

No longer riding St. Christopher

Not dancing

Nor pouring her heart out/in ink.

And brothers, father, mother, family $\&$ friends ache and $\&$ make do.

Yet from beyond and through

Her continuance, still aRRiving

descending: lighting

Everywhere and always

riding, dancing

pouring

Nowhere and now here.

Even in this poem by someone with no training, formal or informal, one finds a grasp of the significance of the smallest elements of standard poetic language: language play that embodies a philosophical stance toward its subject matter ("continuance," "nowhere and now here" invoking the Buddhism that has made sense of life under emotional duress); internal rhyme ("ache and make do"); thematic invocation of a series of overlapping/juxtaposed cenotaphic surfaces - monument, tombstone, 
computer screen, printed page, matchbook cover - on which a life is written and unwritten; the inscription of affect in orthography (“äRRiel”/“aRRiving”). There is much skill in this expression of suffering. ${ }^{2}$

Ariel took the cybername äRRiel for her strong presence on MySpace where she helped set up safety mechanisms for its participants. She rode a chopper bicycle with SCUL (Subversive Choppers Urban Legion) under the name Pigpen, designed and executed drawings for 'zines as well as writing her own superhero comic book (Dirty Gurl Chronicles, whose cover shows its heroine, a street kid who found the superpower-conveying garment while dumpster-diving, asking, "Does this leotard make me look fat?") and marketed her punk fashion patches over the web. When Susie told me about SCUL's Pigpen Memorial Ride through Someville and Cambridge, I told her I wanted to write about it, but had to find the right moment. This is it. That is, beyond the presence of the conventially "poetry" in elegiac, funereal or memorial contexts - that is, the highly charged, formal verbal artifacts intended as lyric - the rituals surrounding such events are themselves highly charged with a haptic or kin/syn-aesthetic energy, a poetics that requires some descriptive effort including thumbnail sketches of "colorful characters," uses of subculturally specific jargon, and so forth.

The SCUL Pigpen Memorial Ride, a parade on wheels, was one such mourner's procession (akin to the New Orleans funeral march phenomenon). It comprised a varied group of bicycle bricolage geniuses, including: Skunk, the founder of SCUL (www.scul.org/SCUL/Pilot/Pil_Skunk.html), who, according to Annie Kessler, a friend of Ariel's family,

came equipped (he was a work of art himself!) ... with a handmade leather belt made from cast-off found materials; the belt contained a hand-sewn leather pocket/purse-like thing in front that opened to show a full line of bike repair materials in it to help in case anyone's bike broke down. Also he had on him some outlandish gear, he wears dresses and handmade boots fashioned out of large pieces of rubber, with brass screws all around to keep the boot-shape in place. He came with boxes of bike-bells so we could all make our bells work in unison at appropriate times on the ride, to memorialize Ariel. He mounted bells on each bike as each person arrived.

Susie, the bereaved,

rode on the back of a two-seater, an old old bike, with Skunk ... who had a cooler; while we were riding he'd pass people drinks from the cooler. It was a big old cooler with ice in it! We rang the bells consistently while we went through Harvard Square [where Ariel spent a lot of time in the "subway pit," as do many homeless kids]. (Lannen)

Tightgirl, a six-foot-tall, highrise-platform-shoes-and-skimpily, bare-midriffed blackbikini-w/-orange-pompom-tassels-with-lacy-black-evening-jacket-wearing tattooed and heavy black booted Unitarian Universalist minister, a chaplain at St. Elizabeth's 
Hospital with long blond hair in ponytails that stuck straight up ("you gotta dress up when you're celebrating someone's life"), who attracted a lot of attention during the ride, and whom it was impossible to look away from; and others (see "The Pilot Standings" under "Personnel" at www.scul.org/SCUL/SCUL.html for the full cast of characters with nicknames, pictures and verbal profiles). Everyone wore colored cloth armbands saying "PigPen is my Co-Pilot" and also tied them around bikes, waists, necks, heads as banners, flags, sashes, sweatbands, riding disassembled and re-assembled bicycles festooned with cheerleader-tinsel streaming out of handlebars, bicycle equivalents of bumper stickers, paste-on stars, and so forth. The chopper phenomenon and SCUL "look" are here described by Kessler, whose participation in the ride was her first exposure to SCUL:

The bikes were of a big variety of unusual concoctions that people had put together themselves: handmade bikes made from parts of other bikes, and parts of other nonbike things as well: one bike had a piece where the handlegrips ... well, underneath the whole frame of the bike shifted to the right or left like a hinge; you'd be holding your hands off to the right or left but your seat would still be going forward; really dangerous and really fun. Unusual bikes, with seats 10-12 feet up in the air, pedaling by other means; tandems, three-wheelers, low-riding concoctions with low seats ... interesting vehicles. The people on them (thirty-six in all) [were] kind of shocking physically because of their hair, their dress, their tattoos, their piercings, [there was] a lot of shock value in the look.... I'd been to the memorial service and I knew how open and loving they were; a lot of people would have been scared of them though, the Goth look, the chains and all black.... There were teachers, fathers, carpenters, married people ... all ages, not just Ariel's age; lots of professional people. A good slice of Americana.... Later for dinner we gathered at a very cool restaurant in Cambridge and of course there we talked about Ariel. It was a one of a kind experience, the experience of a lifetime; I'd do it again this year if I could, if they're doing it again. I've never experienced anything like it before.

She also described the extremely well-organized ride, the maps that were handed out, the idiosyncratic terms for taking a left or right turn, for warning about oncoming traffic, and the rhythm of the way this information was called from one bike to another back through the cortège, the iteration-and-difference of the verbal relay, the way she felt protected by the group and Pigpen's strong presence; people were wearing her designs, riding her bikes, and wearing her name on their bodies. These objects and their continued utility constitute forms of elegiac creativity intended to invoke her presence, as does a quilt that was made for her by her SCUL friends.

The prose that has continued to well up and manifest in the aftermath of Ariel's passing, the messy punk designs, Ariel's own writing still available on MySpace

("I walked through Harvard Square in a daze almost, only trying to get to the bus stop, but there was so much between that bus 
stop and me.

I saw the ghosts of payphones, now only oddly shaped holes in the brick sidewalk. I sat on those benches so many times, often crying. Sometimes I wonder how many tears are in the wood of those benches, the desperate tears of junkies. Like me."33),

that of her cyberfriends who still write to her there, these are elements of a poetic micro-climate flourishing in the highly commodified environment of MySpace which has become a conglomerate ploy to capitalize on youth's need to be connected, that furious yearning drive outward that finds fulfillment in a combination of vulnerable self-disclosure and anonymity, proximity and distance, solipsistic fantasy and tentative reaching-out. Susan's poem, the chopper parade, äRRiel's website and its continued life through her punked-out, lively friendship network and the continued availability of her "gorgeously rough-hewn, deftly narrated, and frank first-person prose" (Dodero) are all facets of a microculture that is highly poetic.

Now does that mean "poetic"? In this case, the vivid language resides not only, though most importantly, in Ariel's surviving language-presence but in the ritual languages of SCUL: the name each member takes on (Skunk, TightGirl, PigPen; Ariel's parents, Larry Dobie and Susan Lannen, were affectionately addressed by SCUL members as "Mr. Pen" and "Ma Pen" respectively), the names members gave their bikes (Ariel's two bikes were St. Christopher, a heavy blue craft with yellow stars and blue tinsel streamers; and Man's Ruin, a lighter bike), and their idiosyncratic vocabulary form a linguistic constellation charged simultaneously with efficiency and awkwardness, the "compactness" and "defamiliarization" so intrinsic to mainstream poetic values. Their vision, counterculturally activist, is highly selfconscious and enjoined with a sense of play. The "philosophy and creed" announced on SCUL's website (subtitled "The Counterculture to Americas Love for the Automobile"), for example, typos and all, assert the values of form over function, the aesthetically-motivated defamiliarizing of that form in the interest of missions rhetorically (only partly tongue-in-cheek) associated with the military but obviously aligned with the poetic, the bricolaged, the aestheticizing/functionalizing of found materials (see Appendix I). Under a heading called "SCUL lingo," the fanciful space-movie/military jargon of this "constantly evolving dictionary" spells out a functional sociolect reflecting the political aspirations and low-tech values of the group; a "CBU: Carbon based unit. A person, usually someone not in SCUL;" "Clip: One dozen donuts;" "Fuel: coffee;" "H.A.R.V.: High Altitude Reconnaissance Vehicle. A Tallbike;" and so on.

$$
* * *
$$

Another elegiac set of events saturated in the poetic was the aftermath of the passing of Lyx Ish, aka Liz Was, aka Elizabeth Pearl Nasaw, co-founder of Xexoxial Editions and Dreamtime Village, writer, musician, herbalist and den mother to the upper Midwest avant-garde. A parade through the small town of LaFarge Wisconsin, similar to the bike ride for Ariel, as well as a number of objects (a pair of boots, handmade musical instruments, a gourd on a bedsheet) super-saturated with Lyx's 
presence, is described in a special elegies section of online journal BigBridge (see Appendix II). In the same special section, mIEKAL aND, who had been Was/Ish's partner for seventeen years, posted a koanic visual poem he had written for her after she lost her powers of speech but before she died:

\author{
Hello Below the Serif of Indestructibility \\ Even what to hold on to? \\ A boggle of speakers. \\ Come alive when \\ thinker is no longer speaking. \\ Can I come aboard? ${ }^{4}$
}

a haunting question mark hovering behind the words. Later I cross-stitched this poem. ${ }^{5}$ A site of collaborative poems at a wiki, Writing Dubuffet's Titles, was also dedicated to Elizabeth Was (and to visual poetry pioneer Bern Porter) ${ }^{6}$, as is a memorial site (www.gourdgoddess.net/) and a tribute on Dreamtime's homepage. ${ }^{7}$ In this case, the participants and artists already conceived of themselves as poets, unlike Susan and others, who have been catalyzed into the poetic through the trauma of sudden loss. However, one can still witness the degree to which the death of loved ones galvanizes a drive to create that seems bound up in the primal set of urges Freud initially theorized. Could it be that, rather than simply instances of sublimation, these creations spring out of some nexus, some meeting place, some dialectical jouissance, of the pleasure principle and whatever lies beyond it? And the elements of movement through familiar and meaning-saturated space (the processions), food, a shared community meal, and conversation about the beloved absence, are instinctive ways of creating social order around the torn fabric of everyday life in the rituals surrounding death, even in these alternative subcultural enclaves. A cultural-studies approach to elegy that would blend literary theory with ethnographic attention to specificity would be a useful though vast project, toward which the foregoing are merely breathless notes.

\title{
3. Final Visitation: Mike Chasar's Cues, My 'Aze:
}

MC: What reading have you been doing of late (with an eye toward its relevance to further discussion of micropoetries)?

MD: 1) Weird English, by Evelyn Nien-ming Ch'ien, offers a highly poetic and sociocultural analysis of the strange Englishes used by immigrant communities in both everyday and literary life. The introduction makes a spirited argument for the social value and scrutability of unusual Englishes, as well as their purposeful and skilled deployment by their users. "I am work hard my whole life, and fierce besides," is the first of five literary examples Chi'en offers (5); she continues by outlining in excitingly non-abstract but rigorously demonstrable terms several criteria for determining the mechanisms and aims of "weirding" English:

1. Weirding deprives English of its dominance and allows other languages to enjoy the same status;

2. Weird English expresses aesthetic adventurousness at the price 
of sacrificing rules;

3. Weird English is derived from non-native English;

4. The rhythms and structures of orthodox English alone are not enough to express the diasporic cultures that speak it. (11)

But it is in the poetry of her own language and that of her subjects, as well as the "aesthetic adventurousness" of the enterprise itself, that leads me to link this book with the concept of micropoetries. It is in detecting the demotic and daemonic (in the sense of impish rather than Satanic) lineage behind highly literary prose that we find useful formulations concerning the social purpose of non-normative poetries by the communities that generate them, embed them in their daily social practices as well as set them off as special in their aesthetic rituals (the open mic, the "special song" or self-written text at the "commitment ceremony," the invention of names for children in dissident communities, etc.). Although much of the book treats uncontroversially literary figures like Vladimir Nabokov, Arundhati Roy and Junot Diaz, it also features chapter titles like "Chinky Writing" and "The Shit that's Other," as well as subheadings like "Screw Inscrutability," and gives what I might term "écriture brute," "artisanal/guerrilla poetics," or "diaspora poeisis" ("poeisis" rather than/as well as "poetics" to indicate its continually fluctuating and becoming nature) its own equally analytically and aesthetically compelling status.

2. Published in Workers of the Word Unite and Fight, a chapbook by Mark Nowak from Palm Press, an essay, "Neoliberalism, Collective Action, and the American MFA Industry," has been getting wide circulation in the poetics world. Nowak's work has become, over the years, more overtly Marxist in its language, analysis and techniques, and this essay brilliantly links the "neoliberal language industry" with other forms of capital-flow in the era of globalization. As a counter to the collusive role of academic MFA programs that, in Nowak's argument, train a workforce of language technocrats for either rulership or, more often, abject workership within an oppressive system (the celebrated author, the underpaid chain-bookstore cashier, the librarian, the adjunct or part-time teacher, the tenured professor, the freelance tech-writer, the enrollee in the "cash cow" program that subsidizes $\mathrm{PhD}$ programs and tenured Creative Writing faculty at major universities, the unpaid editors of literary journals, the judges/applicants/sponsors of expensive literary contests, etc., etc.), Nowak describes several alternatives that focus on collective action rather than the current U.S. experience of atomized economic suffering and anomie coupled with the fetishization of the creative writer as solitary visionary. While the parallel Nowak posits between the global economy and the machinations of the U.S. creative writing industry is brilliant and productively provocative, he does not attend thematically, in this essay at least, to writing practice itself (though the essay itself enacts a writing practice, as do Nowak's other projects), either in the workshop model he indicts or in the alternative collective actions in which he finds inspiration. However, he does enumerate alternative institutions both historical and extant: among them John Reed Clubs, Ernesto Cardenal's poetry workshops for Nicaraguan workers, the occupation of abandoned factories in Argentina by workers who, among other things, stage Brecht plays and operate lending libraries in the sites of their former exploitation. Nowak is currently teaching creative writing in a 
Ford factory in St. Paul, MN, that has been slated to close; the workers have written and videotaped a reading of their poetry about the impending closing. Nowak has contacted similar factories in South Africa and sent videotapes of the reading; he will be there leading workshops for South African Ford workers this summer. In the sense that he addresses language and literary activities as a whole (not separating out the activity of "writing poetry" from other forms of literary labor), Nowak's work continues to enrich the possibilities of "micropoetries" by dwelling not on the print-product of "poems" but on a wide network of poetic/language activities both oppressive and emancipatory.

3. For another take on the MFA industry, this one focusing on the limitations and potential revisions of the workshop phenomenon, poet Steve Healey's unpublished essay "Creative Writing in the Society of the Spectacle." Though the piece's title nods to Guy Debord's lament that all social phenomena have become commodified into the realm of the spectacular (beyond even being commodified and fetishized as objects), it does not take Nowak's turn to language-labor activism but rather speculates on a different kind of workshop experience, one based on generating material as a collective of individuals, rather than taking the lead from a tenured expert in learning how to evaluate poems already written in the prescribed post-Romantic labor-intensive solitude. Healey, himself an MFA graduate who has taught writing in prisons as well as university settings, advocates a more lively, onsite writing practice (akin to what he's found works in prisons as opposed to the academic mode) that is rooted in the present, the interactive, the process, in order to erode the fixity of the finished poetic fetish object, which then becomes subject to commodification and entered into an economy of hierarchy, consumption and profit that is, as Nowak argues, inseparable from the machinery of acquisitive globalization. This analysis of the inner workings of the Creative Writing industry from a global perspective expands interdisciplinary approaches to theorizing creative writing as an institution as well as a practice, and has implications for micropoetries to the extent that there is a "bottom-up" rather than "top-down" influence afoot: it is the dynamic and high-stakes experience of prison teaching that has led (at least for this scholar/teacher/poet) to the overhaul of academic writing practices, rather than vice versa. He sees the pro- and con- arguments about the workshop model of Creative Writing instruction as two elements of a self-sustaining dialectic; rather than stick with the status quo or throw the baby out with the bathwater, Healey proposes what he terms a "generative" workshop model based on his experiences teaching writing in prisons; such a model, in which writing takes place and is shared, would replace the "evaluative" model that currently operates in most (but not all) institutions, in which completed work most often rendered in solitude is brought in for peer and expert evaluation - a model that replicates in microcosm the competitive world of capital, cultural or otherwise, that the students have signed up to be groomed for.

4. Another Mark Nowak project, Xcp: Cross-cultural Poetics 16: Word, comprises a dictionary of keywords compiled from just over a hundred individual contributors who defined a word of their choice in 250 words or less. The range, from previously unpublished immigrant students defining "education" or argot specific 
to their generation and language group, to Amiri Baraka on "God," Paula Rabinowitz on "object," Lisa Arrastia on "gangster," etc., and a host of strange and wonderful preoccupations "hypnopompic" (Sesshu Foster), "manner, manners" (Jen Hofer), "phoneme death" (Ed Pavlic), "it's too early to say" (Rodrigo Toscano), as well as the rethought familiars "ideology," "hybrid," "jihad," "neighborhood plan," creates a dense and yet expansive texture of thought, word, analysis, imagination that exemplifies a collectivity whose totality exceeds the sum of its parts, a critical mass that galvanizes the reader to think more carefully about received terms and to dare come up with new coinages that inscribe new or revised analytic categories. What this does for a conception of micropoetries is to once again direct the reader/ thinker/writer to the minutiae of individual words that make up our everyday environment and reinfuse them with rigor and vigor.

5. Walter Benjamin, "Theses on the Philosophy of History" (again). For many years Benjamin's essay "On Some Motifs in Baudelaire" had been my gold standard of writing about poetry. More recently, however, the more famous "Theses," with its plea that "nothing that has ever happened should be regarded as lost for history," speaks to the importance of the "micro" in all its senses but particularly, including but beyond the literal sense of scale (smallness, easiness to overlook), the sense of ignominy, abjection, forgettability, eccentricity, undesirability, wrongness (255). The last thing Benjamin wrote before he killed himself believing he would not be able to escape the Nazis, the "Theses" exhort its writer's intellectual heirs to attend to every bit of detritus and debris, every life and every social and human phenomenon. The urgency of the message, a kind of S.O.S. in a bottle flung in a last act of faith in rigorous, engaged creative thinking whose primary aim is human emancipation, translates well into a concern with the heightened charge of micropoetries and poetries which may well go unattended unless one learns a new way of listening. It is always Benjamin's conviction that language and material objects share strange, hidden and multiple resonances that make his work particularly relevant to poetry scholars whose focus is the morpheme, the phoneme, the letter, the stutter, the many glottal villages we move through unconsciously: the smallest bits of linguistic stuff that constitute the social environment on which our lives depend. The Arcades Project is likewise relevant to a study of micropoetries for obvious reasons formal, thematic and metathematic (conceptual); in the radical freedom of Benjamin's associative and dialectical imagination, he permits himself to create new word-worlds wherein the relations between things, thoughts and language are illuminated, complicated, enriched, deepened, invented and discovered.

6. A host of events: a visit to the U of MN by Ammiel Alcalay, who spoke on "networks of trust" in the international writing/translating/publishing arena and how his own publishing projects were gravitating toward smaller and smaller presses, as experience has shown him that works find their proper audiences and that these sustain the life of a book far beyond what a for-profit or major academic press might be willing to subsidize. Likewise a visit from Adeena Karasick, whose Kabbalistically-informed poetry tends with exquisite care to the visual page-aspects of poetry: a letter is a micro-poem, a visual poem, an inexhaustible resource of "fiery potential." In her performance style, a tour-de-force of shape-changing from 
Brooklynese spoken word hip-hop style to valley girl to scholarly delivery, she enacts the Kaballah masters' exhortations to make even the movements of the head, the shape of the speaking mouth, become part of a linguistico-spiritual system of achieving union with the world seen and unseen. ${ }^{8}$ Gabrielle Civil's Poetry Circles, a series of five-week sessions of weekly two-hour meetings offered free to the public through Minneapolis writing center SASE (pronounced "SASSY") bring some of Bard College's Institute for Thinking and Writing techniques together with Gabrielle's flamboyant and generous brilliance: we've read/written on/riffed off of Ann Carson, Jayne Cortez, David Hinton, and others. Alan Sondheim's ongoing, unspooling, endless generation of work that along with that of Karasick and Walter Benjamin (among countless others) comprise a diasporic inclination toward excess - what I've been calling a diaspora poeisis in recognition of its unfinishability, its constant in-process-ness. And the ongoing online adventures of the Flarf collective who revel in badness, culling from the internet via Google searches for the most banal, clumsy, offensive and sentimental detritus available phrases that, linked into paratactical sallies on poetic decorum, make for much laughing aloud. What Flarf does for micropoetries, in spite of the obvious self-consciousness of this work as "cutting-edge," is to turn all the most taboo matters in poetic convention into the very matter of poetry itself, asking us to see poetry in the rawest and most abject of human social data. Joseph Harrington's Poetry and the Public, which was one of the earliest books to give newspaper poetry and activist poets like Arturo Giovanitti its day in the foreground.

MC: How is this reading helping you recalibrate what "micropoetries" are and what "micropoetics" do?

MD: By blurring the boundaries between literary, para-literary, non-literary and post-literary poetry, and by widening the definition of poetry, one might want to make large claims that the very micro-ness of the micropoetries handle allows us macro-access to wordmagic, concentrated, consciousness-altering language, that is not necessarily within the purviews of literature, that might, in fact, not be words at all, though they are signifying systems used by humans. This gets close to an aesthetically-weighted cultural studies (of which Benjamin's projects are the paradigmatic example), or a semiotics that emphasizes the phenomenological effect of language and its socio-aesthetic impact on both micro/local and macro/global scales.

MC: How is this reading leading you in ways that other scholars might find helpful or challenging for their own research?

MD: I'm not sure that's for me to say. It's hard to predict what other scholars may or may not find useful, but I suspect that what appears initially to be eccentric or peripheral ends up often being the most productive insight for others, though they - or its author-may not realize it enough to be able to acknowledge it at the moment. I'm delighted to see that the work I was most excited about twenty years ago is finally coming center stage in, of all places, the MLA's Poetry Division. I think what continues to challenge is the need to cultivate a principled (and contingent, if that makes it easier for some) disregard for "evaluation" along conventional lines, a disregard that is nonetheless not bogged down in a plodding or depoliticized historicism - a degraded but widespread and institutionalized result of Foucault's 
and others' hard-won post-' 68 gains. Aesthetic pleasure (simultaneously interested and disinterested) as experience can exist independent of judgment, Kant's rhetorical sleight-of-hand regarding the postulatability of universal judgment notwithstanding.

MC: What uncharted territories are coming into your sights, and what is the promise those directions hold?

MD: Ultimately, nothing new but the continued blurring of everyday life and poetic language so that every moment, object and interaction - on the immediately personal register as well as in the many public spheres we inhabit-has its poetic dimensions and with those dimensions, a healthy series of debates about keeping an "outside" alive and pressing on the borders of our capacities which will, eventually, find a way to incorporate some version of that "outside" - at least partially. If we could learn to experience life in these poetic borderlands, increasing through practice and attention our ability to stay there for longer durations, perhaps we would not need to fight over resources in ways that bring about such dire planetary consequences as we have witnessed these last few years. These are large claims, thoroughly experiential in ambition, but why not? What else might be worth aiming for?

Appendix I:

\author{
SCUL Philosophy and Creed \\ (http://www.scul.org/SCUL/SCUL.html)
}

We are a gang who like to ride strange vessels called CHOPPERS. They are radically modified bicycles. Modified to suit our needs.

Most engineering goes on the axiom that form follows function. This is not the case with the bicycle chopper. We let form prevail, and make the function happen forcefully. If we tried to create efficient, easy to pilot machines the result would be a regular bike. SCUL creates bikes that are difficult to control, damaging to knees, and painful to sit upon. They are structurally unsound and easy to crash. We are test pilots of poorly designed vessels. The single advantage that choppers have over other bikes is that they are better at running over empty Burger King shake cups.

Scul Fighters are made mostly from derelict craft, transformed from civilian to military craft. Any reports of derelict craft in local systems should be reported immediately to the SCUL Department of Derelict Craft Retrieval (SDDCR). It is imperative that this information is relayed quickly, before the craft is retrieved as space junk. Derelict ships have several advantages. First, the cost of retrieving the ship is much lower than buying a used ship. Secondly, it is easier to transform a civilian craft than to build a military one from raw materials. Also it is noble to rescue these beautiful ships and use them again as protectors of peace. Lastly these ships possess special traits that are subtle yet powerful.

The SCUL pilot defends the bicycle and pedestrain population in a leisurly manner. 
Appendix II:

\author{
Lyx Ish Memorial Celebration \\ (http://www.bigbridge.org/issue10/elegymdamon.htm)
}

Random splurtlings' impressssionistic:

A wonderful drive in gray weather, just cool enough, just early enough ( 8 am on a Saturday) for smooth interstate sailing. I made it in three hours or so, perhaps a bit longer, following mIEKAL's directions, dipping way into Amish country in the hills and refuges of the driftless grottoes supreme of southwestern Wisconsin. Got to Lyx's house in Lafarge ("right behind the hardware store on Main Street, pretty straightforward") which was full of hippies making breakfast. I went upstairs to look at Lyx's last place of rest, her bedroom with a single maternal-looking gourd on the sheets. The gray and white cat still sleeping on the chair, clearly missing her. Bright things all over: hyacinths, daffodils, dried wondrous curly weeds, handmade cards tacked to the wall ("GET WELL SOON"), a large golden Buddha in the corner, a low table spread with [homemade] musical instruments, stringed-another room full of wind instruments, many huge gourds that had been turned into sax-like reed-axes...It's hard to cover as much ground as I'd like, get down all the magical details of her space, the delightful free-form tiling jobs, the red bathtub, her fabulous shiny black lace-up boots still in her closet. I remember admiring them once when she was wearing them and she said she'd gotten them for a song at a thrift store, and today they were as shiny as they were back then, maybe five years ago, as if she'd just polished them. I love those boots, to me they are Lyx. There were wondrous dress-up clothes in the walk-in closet. I feasted my eyes (how's that for a cliché) on all of the life-art art-life minutiae in every moment and every corner. In one room there was an enormous gilt and flowered Asian (Japanese?) fan over the bed, like a protecting angel.

I went downstairs and there were some people knitting so I joined them w/ my $\mathrm{x}$-stitching. One guy also was Danish and knew about Danish needle arts so that was fun. There was an Ojibwe Lac de Flambeau guy there, Nick Hawkins, who later did a ceremony with tobacco and prayers. Boa, who co-owned the house w/ Lyx, had asked him to come down. Boa was wearing a pink and purple knit hat. Everyone was wearing imaginative and colorful clothing. But nothing like what was to come. Kids and grownups with clown make-up and wild clothing, mylar kites, wind and percussion instruments galore, party clothes in the finest anarcho-hippie tradition, a whole row of us carrying dijeridoos - trumpet, trombone, sax, and gourd (played by mIEKAL); lots of videographers running alongside and among all the paraders. Zon [Lyx's and mIEKAL's son] whom I hadn't seen in years has shot up and is a handsome young man with a lot of presence. He was wearing a red velveteen jacket and camouflage fatigues. I guess he was exhausted from recent events and from dj-ing an audio-wake for his mother the last few days but he was very in control of events and showed a lot of leadership, just like his mother. A lot of kids and dogs were there. The kids were of all ages. Some were wearing bright colored bathrobes of plushy material. We walked en masse a few miles to a beau- 
tiful stark park and Boa had Lyx's ashes in a gourd she had made. We each took some ashes, they were a lot darker and more bitter-tasting than my Uncle Al's from a few years ago-and we scattered them about, into the Kickapoo River, which was flowing very swiftly under a wooden bridge a lot of us stood on. I was most touched when mIEKAL first emptied his hand of the ashes, then took a bell off from the string of bells around his neck and dropped it into the river and finally took his magnificent gourd-sax and hurled it into the river as well. There was drumming the whole time, and someone all in black wearing a death's head walked up and down the bridge, stomping a walking stick on the ground in time to the beat. Then Nick Hawkins had us each take some tobacco from his beaded pouch with our left hands (closer to the heart), put some back on a cloth that he was going to take back up to the Lac de Flambeau rez, then we sprinkled the remaining tobacco around - i dropped mine back into the river, and looked to see if the gourd-sax had caught on a snag downstream - i think i saw it; i could hardly bear the idea of it just drifing somewhere to get caught and rot, but i guess that is my limitation as a hoarder.

Then Allegra had us gather in a circle and people said things about Lyx, or played instruments (a brilliant androgynous saxophonist, Joannarchy, did something cool) and Zon and mIEKAL both spoke as did many others in their bright garb and joyous mien. Her yoga teacher Kalim was there. He sang a song, shu mama shu something, i love you i hope you love me too. We tried to sing along. We sang some other stuff and struck some yoga poses. After a few hours we went back to the house and then went to the community center down the block for a dinner. Camille [mIEKAL's partner] had made wonderful traditional Romanian funeral food, a combination of wheatberries, honey, walnuts and a bit of chocolate chips. Walnuts stood for the threshold between life and death, wheatberries for I can't remember, honey for Lyx's qualities and values in this life. We each tasted it and thought of Lyx. It was in the basement of the community center with long tables and folding chairs. It was a very community-ish feeling. I saw some folks I recognized from brief trips to Dreamtime over the years. I am not really a part of the community but a fellow-traveler of sorts but people were very nice and Lyx was an obvious topic of conversation so there were no awkward silences. Lyx was an extraordinary person and everybody recognized it and acknowledged it. She is still. It seemed a little strange not to have her there but I guess that's what it was all about. Whenever i am given the ashes of a person i try to ingest just a tiny bit. I guess that is called anthropophagy and is a very common mourning rite, or at least Allen Ginsberg told me that when i asked him about it in 1996, a few months before i met mIEKAL and Lyx and embraced Dreamtime and Xexoxial into my world. There was going to be a party at Dreamtime later but $\mathrm{i}$ hit the road so i could sleep in my own bed instead of going to the bed and breakfast i'd planned on. So now i'm home after the 3.5 hour drive listening to all kinds of wonderful People's Music on the radio. It was snowing and blowing but $\mathrm{i}$ was very warm, a bit too warm, had to keep opening the window. Sweet dreams, Lyx and everybody. 


\section{Notes}

1 Another inspiration for the term "micropoetries" was that of "micromovements," choreographer Emilie Conrad's coinage to describe the smallest perceptible movement that a person can deliberately initiate and sustain in any part of the body. She has incorporated this concept into the system of movement awareness entitled Continuum, and into work with paralytics and other movementchallenged people. Thus the term refers to a minute but effectively expansive technique for restoring abilities; in the same way, "micropoetries" aims at dealienating poetic language from everyday life.

2 "I was taking a class in therapeutic writing for my MA program [in expressive therapies]; I opened up one of the textbooks for the class [Gabriele Rico's Writing the Natural Way] to a page of writing by someone who had seen the Viet Nam Memorial. I couldn't stop working on it until it found its final form the next day; I used a technique we'd learned in class, 'clustering'... I couldn't think about anything else until it was done. It was my way of dealing with what I had read [the Phoenix article on virtual memorials]; it was hard to read and I had to deal with it through creative energy." (Lannen)

${ }^{3} \mathrm{http}: / /$ arrielgurl.livejournal.com/

${ }^{4}$ http://www.bigbridge.org/issue10/elegymand.htm

${ }^{5} \mathrm{http}: / / \mathrm{www}$.spidertangle.net/liquidtext.com/lyxstitch.html

${ }^{6} \mathrm{~h} \mathrm{t} \mathrm{t} \mathrm{p} \mathrm{:} \mathrm{/} \mathrm{/} \mathrm{j} \mathrm{o} \mathrm{g} \mathrm{l} \mathrm{a} \mathrm{r} \mathrm{s} \mathrm{.} \mathrm{o} \mathrm{r} \mathrm{g} \mathrm{/} \mathrm{E} \mathrm{n} \mathrm{t} \mathrm{e} \mathrm{r} \mathrm{W} \mathrm{r} \mathrm{i} \mathrm{t} \mathrm{i} \mathrm{g} \mathrm{/}$ i nd ex.ph p ? p a ge n a m e = W r iting D ub uffets Tit le s \& PHPSESSID $=\mathrm{c} 026 \mathrm{e} 953 \mathrm{~d} 7 \mathrm{c0cd} 364 \mathrm{f} 96 \mathrm{c} 9 \mathrm{a} 76 \mathrm{e} 33 \mathrm{ee} 19$

${ }^{7} \mathrm{http} / /$ www.dreamtimevillage.org/

${ }^{8}$ See, for example, her Dyssemia Sleaze. Toronto CA: Talon Books, 2000; and The House that Hijack Built. Toronto: Talonbooks, 2004.

\section{Works Cited}

Abou-Lughod, Lila. Veiled Sentiments: Honor and Poetry in a Bedouin Society. Berkeley: U of California P, 1986.

Benjamin, Walter. “On Some Motifs in Baudelaire.” Illuminations. Trans. Harry Zohn. New York: Schocken Books, 1969. 155-200.

—. "Theses on the Philosophy of History." Illuminations. Trans. Harry Zohn. New York: Schocken Books, 1969. 253-264.

- - . The Arcades Project. Ed. Roy Tiedemann. Trans. Howard Eiland and Kevin McLaughlin. Cambridge, Mass.: Harvard UP, 1999.

Caton, Steven. "Peaks of Yemen I Summon": Poetry as Cultural Practice in a North Yemeni Tribe. Berkeley: U of California P, 1991.

Ch'ien, Evelyn Nien-ming. Weird English. Cambridge, Mass.: Harvard UP, 2004.

Damon, Maria. "Micropoetries.” Xcp: Cross-Cultural Poetics 15/16, Word Issue: (2006): 235.

—. "Post-literary Poetry, Counterperformance, and Micropoetries." Class Issues: Pedagogy, Cultural Studies, and the Public Sphere. Ed. Amitava Kumar. New York: New York University Press, 1997. 33-47.

_. “Tell Them About Us.” Cultural Critique 14 (Winter 1989-1990): 231-257. 
Dodero, Camille. "They Have MySpace in Heaven, Right?: Inevitably, the socialnetworking site has become a virtual graveyard." The Phoenix (Boston) online. 28 Mar 2006: <www.thephoenix.com/Article.aspx?id=7187\&page=1>

Dubois, W. E. B. "Of the Sorrow Songs.” The Souls of Black Folk. New York: Signet, 1969, 264-277.

Gates, Henry Louis, Jr. The Signifying Monkey: A Theory of Afro-American Literary Criticism. New York: Oxford UP, 1988.

Harrington, Joseph. Poetry and the Public: The Social Form of Modern U,S. Poetics. Middletown, CT: Wesleyan UP, 2002.

Healey, Steve. "Creative Writing in the Society of the Spectacle." Unpublished.

Kessler, Annie. Interview. 30 May 2006.

Lannen, Susan. Telephone interview. 31 May 2006.

Miller, W. Flagg. Resonant Letters: Poetry, Audiocassettes, and the Moral Authority of Media in Yemen. Cambridge MA: Harvard UP: forthcoming 2007.

Nowak, Mark. "Neoliberalism, Collective Action, and the American MFA Industry." ¡Workers of the Word, Unite and Fight! Los Angeles: Palm Press, 2006. 7-23.

Nowak, Mark, ed. Xcp: Cross-cultural Poetics 15/16: Word Issue (2006).

Rimbaud, Arthur. "Alchemy of the Word." A Season in Hell. Trans. Delmore Schwartz. Norfolk, CT: New Directions, 1939, 69.

Sacks, Peter. The English Elegy: Studies in the Genre from Spenser to Yeats. Baltimore, MD: Johns Hopkins UP, 1985).

Slobin, Mark. Subcultural Sounds: Micromusics of the West. Hanover, NH: Wesleyan UP, 1993. 